\title{
Experimentando a Zoologia: alteração na coloração corporal do Escorpião-amarelo (Tityus serrulatus) por meio da luz negra
}

\section{Experiencing Zoology: Changing the body color of the Yellow scorpion (Tityus serrulatus) through black light}

\author{
Tiago Maretti Gonçalves ${ }^{1 *}$
}

\begin{abstract}
RESUMO
A Zoologia é a área da Biologia que estuda os animais, em relação a sua morfologia, fisiologia, evolução, sistemática, e até aspectos comportamentais. No entanto, é uma área com um aporte teórico muito extenso, podendo desmotivar os alunos. Para contornarmos essa problemática, o presente trabalho possui como principal objetivo facilitar a aprendizagem e despertar a curiosidade dos alunos na disciplina de Biologia, no Ensino Médio, no que tange a área de Zoologia, sobre os quelicerados (escorpiões), por meio de uma atividade experimental demonstrativa realizada pelo professor utilizando um espécime não vivo do "escorpião-amarelo" (Tityus serrulatus). Nessa atividade, o professor irá demonstrar aos alunos, como a ação da luz negra incidindo sobre a superfície corporal do escorpião-amarelo no ambiente escuro o fará mudar de cor, exibindo uma coloração azul fluorescente. A atividade ainda, permite ser um eixo integrador de outros assuntos da Zoologia no que tange a Morfologia, Fisiologia e medidas de prevenção para se evitar acidentes com esse animal tão fascinante e peçonhento como é o escorpião-amarelo.
\end{abstract}

Palavras-chave: Ensino; Escorpião-amarelo; Experimentação; Quelicerados; Zoologia.

\begin{abstract}
Zoology is the area of Biology that studies animals, in relation to their morphology, physiology, evolution, systematics, and even behavioral aspects. However, it is an area with a very extensive theoretical contribution, which can discourage students. To get around this problem, the main objective of this work is to facilitate learning and arouse the curiosity of students in the discipline of Biology, in High School, regarding the area of Zoology, about chelicerates (scorpions), through an activity demonstrative experiment carried out by the teacher using a non-living specimen of the "yellow scorpion" (Tityus serrulatus). In this activity, the teacher will demonstrate to the students how the action of black light falling on the body surface of the yellow scorpion in the dark environment will make it change color, displaying a fluorescent blue color. The activity also allows to be an integrating axis of other subjects of Zoology regarding Morphology, Physiology and prevention measures to avoid accidents with this fascinating and venomous animal like the yellow scorpion.
\end{abstract}

Keywords: Teaching; Yellow Scorpion; Experimentation; chelicerates; Zoology.

${ }^{1}$ Universidade Federal de São Carlos, UFSCar - SP.

*E-mail: tiagobio1@ hotmail.com 


\title{
INTRODUÇÃO
}

A Zoologia é uma área fascinante da Biologia que estuda os animais, no que tange a sua morfologia, fisiologia, evolução, sistemática, e até aspectos comportamentais. No entanto, no Ensino Médio, ela é encarada por muitos alunos como complexa, por possuir muitos termos que devem ser bem contextualizados (Gonçalves, 2021a). Outro ponto que é determinante para dificultar a aprendizagem dos discentes é o massivo uso pelos professores de aulas baseadas em metodologias expositivas, que causam grande passividade e pouca assimilação do conhecimento em função do déficit de atenção dos alunos (Krasilchik, 2019).

No intuito de vencermos tais defasagens, promovendo maior interesse e potencializado a aprendizagem dos alunos, é de grande relevância a proposta de metodologias alternativas de ensino (Gonçalves, 2021b), e uma delas, são as atividades experimentais aplicadas na disciplina de Biologia, no ensino médio. Nesse sentido, de Albuquerque et al. (2014, p. 260) defendem que:

\begin{abstract}
"A atividade prática promove uma motivação na aprendizagem e uma reconstrução de conceitos que ocorre de modo idiossincrático e mais eficaz, do que uma abordagem estritamente embasada nos fundamentos de uma aula teórico-prática. Os conceitos são trazidos de modo não arbitrário o que concretiza uma aprendizagem significativa, sendo relacionada de maneira satisfatória e eficaz para sua estabilização nas estruturas cognitivas" (Albuquerque et al., 2014, p. 260).
\end{abstract}

Todavia, a abordagem de aulas práticas no ensino de Biologia não é muito comum. Na literatura, Marandino, Selles e Ferreira (2009) relatam que a parte curricular do ensino, pode ser um dos fatores que dificultam o uso dessa metodologia no ensino de Ciências, colocando as atividades práticas como parte acessória do ensino na disciplina de Biologia e não como parte integrante do mesmo. Outro fator impeditivo, pode estar associado a parte física do espaço escolar, ou seja, segundo dados do censo escolar de 2018, uma parcela de $38,8 \%$ das escolas de ensino médio públicas brasileiras, possuem laboratórios equipados para a realização de aulas práticas de Ciências/Biologia (INEP, 2019), sendo ainda um espaço pouco comum dentro do âmbito escolar.

Assim, o presente trabalho possui como principal objetivo facilitar a aprendizagem e despertar a curiosidade dos alunos na disciplina de Biologia, no Ensino Médio, no que tange a área de Zoologia, sobre os quelicerados (escorpiões), por meio de 
uma atividade experimental demonstrativa realizada pelo professor utilizando um espécime não vivo do "escorpião-amarelo" (Tityus serrulatus).

Essa proposta experimental didática, se inicia com a simulação da luz normal (ambiente) em contato com o escorpião. Logo em seguida, as luzes do ambiente serão apagadas, e a luz negra será acesa sobre a parte externa do animal, havendo mudança de coloração da estrutura externa do mesmo, para um tom azul fluorescente.

Nesta etapa da aula, os alunos irão formular e responder as hipóteses acerca do fenômeno observado. Logo após isso, o professor explicará o porquê desse fenômeno. A atividade proposta ainda permite ser trabalhado os aspectos de morfologia externa do animal, bem como sua fisiologia, reprodução e medidas de prevenção para se evitar acidentes com esse animal peçonhento. A atividade experimental não necessita ser realizada dentro de um laboratório, enfatizando ainda mais sua realização pelo professor aos alunos.

No quadro abaixo, estão apresentados, o objetivo, o conteúdo e as habilidades que a presente proposta experimental permite ser trabalhada aos alunos.

Quadro 1 - Objetivo, conteúdo e habilidades trabalhados na atividade proposta.

\begin{tabular}{|c|l|}
\hline Competências & \multicolumn{1}{|c|}{ Descrição } \\
\hline Objetivo & $\begin{array}{l}\text { Facilitar a aprendizagem e despertar a curiosidade dos alunos na disciplina } \\
\text { de Biologia, no Ensino Médio, no que tange a área de Zoologia, sobre os } \\
\text { quelicerados (escorpiões), por meio de uma atividade experimental } \\
\text { demonstrativa realizada pelo professor utilizando um espécime não vivo } \\
\text { do "escorpião-amarelo" (T. serrulatus). }\end{array}$ \\
\hline Conteúdo & $\begin{array}{l}\text { Zoologia dos invertebrados (escorpiões). Morfologia, fisiologia, } \\
\text { reprodução e aspectos de prevenção de acidentes (segurança) em relação } \\
\text { aos escorpiões. } \\
\text { Além de desvendar o mistério sobre o porquê os escorpiões adquirem uma } \\
\text { tonalidade azul fluorescentes, ao serem iluminados sob a luz negra. }\end{array}$ \\
\hline Habilidades & $\begin{array}{l}\text { Desenvolver nos alunos o ato de fazer ciência, utilizando materiais } \\
\text { simples e de baixo custo, além de possibilitar a contemplação de } \\
\text { fenômenos naturais, formulando hipóteses e explicando seus resultados. }\end{array}$ \\
\hline
\end{tabular}

Fonte: Autor (2022). 
$\mathrm{Na}$ atual situação caótica que vivemos, ocasionada pela pandemia do novo Coronavírus (SARS-Cov-2), as aulas têm seguido um modelo virtual ou semi-presencial de ensino. Neste âmbito, a aula pode ser realizada virtualmente, na qual o professor irá demonstrar aos alunos passo a passo conforme as instruções constantes na metodologia. Ao final de aula, poderá ser proposto pelo professor aos discentes, a elaboração um relatório que servirá como meio para avaliação e aprimoramento da aprendizagem.

\section{METODOLOGIA}

Este trabalho, possui natureza didática, demonstrativa e a análise dos seus resultados possui uma ótica qualitativa. Na literatura, Elias, Carvalho e Mól (2017), elaboraram uma proposta didática aos alunos do Ensino Médio, utilizando espécimes preservados de escorpiões a partir da análise do fenômeno do ponto de vista da Química (substâncias orgânicas fluorescentes), da Biologia Evolutiva (possíveis vantagens evolutivas), e da Física (radiações eletromagnéticas envolvidas). No entanto, no presente trabalho, o foco está na área da Zoologia, aplicado aos alunos da disciplina de Biologia no Ensino Médio (2 ${ }^{\mathrm{a}}$ série), com duração estimada de 1 hora e 20 minutos (2 aulas).

Assim, a atividade abordará principalmente aspectos relacionados a estrutura e função do plano corporal dos escorpiões, além de sua Fisiologia bem como boas práticas caseiras, para evitar acidentes com esses animais.

\section{MATERIAIS NECESSÁRIOS}

Abaixo, estão dispostos os materiais necessários para a condução a aula experimental proposta neste artigo.

- Espécime preservado (em álcool), não vivo, do escorpião-amarelo ( $T$. serrulatus);

- Bandeja de plástico branca ou placa de petri;

- Pinças;

- Lupas;

- Luvas;

- Jalecos;

- Lanterna de luz negra (facilmente adquirida em lojas de utilidades domésticas); 
- Lanterna de luz branca normal (pode ser até a própria luz do ambiente).

O organismo não vivo do escorpião-amarelo, utilizado nessa aula prática, poderá ser facilmente adquirido em laboratórios, centros de pesquisas Universitários da área de Zoologia, ou até mesmo em uma repartição pública da prefeitura local, relacionada a zona de controle de pragas e prevenção de zoonoses. Deve ser ressaltado, que o professor demonstre todos os passos explicativos dessa atividade com a espécime não viva de escorpião, utilizando-se uma pinça, oferecendo-se maior segurança aos alunos. Caso o professor permita que os alunos manipulem o organismo não vivo, assegurá-los de usar o jaleco, as luvas e a pinça. Não incidir a luz negra nos olhos, pois a mesma pode causar acidentes.

\section{CONDUÇÃO DA ATIVIDADE PRÁTICA}

Inicialmente o professor deverá apresentar a espécie de escorpião utilizado na aula prática como sendo a pertencente a espécie de $T$. serrulatus (escorpião-amarelo), alertando aos alunos que se trata de uma espécie muito peçonhenta, sendo responsável por vários acidentes e mortes todos os anos no Brasil, principalmente em crianças e idosos.

O professor poderá retirar o escorpião preservado do álcool e acondicioná-lo, na superfície de uma bandeja branca de plástico (ou na placa de petri), iluminando-o com uma luz de lâmpada branca (luz normal ambiente), e os alunos irão perceber que nada ocorrerá. Após isso, será apagado as luzes do ambiente, e o professor irá incidir a luz negra da lanterna, no animal morto, e os alunos irão notar a mudança de cor. Nessa etapa os alunos poderão formular e responder suas hipóteses para o fenômeno ocorrido.

Ao ascender as luzes, o professor irá explicar detalhadamente o fenômeno ocorrido, ressaltando aos alunos toda a estrutura morfológica do animal, além de aspectos fisiológicos e reprodutivos. A atividade prática ainda permite que o docente explique aos alunos sobre os cuidados que todos devemos ter com esse organismo peçonhento que é o escorpião-amarelo, além de ressaltar a ocorrência de outra espécie potencialmente perigosa de escorpiões que ocorrem no Brasil, o escorpião-marrom, representado pela espécie Tityus bahiensis. Para potencializar a aprendizagem dos alunos, o professor 
poderá sugerir uma lista de exercícios acerca do que foi trabalhado, ou a confecção de um relatório com os resultados da aula prática.

\section{RESULTADOS E DISCUSSÕES}

Inicialmente, o professor poderá iniciar a aula prática, apresentando aos alunos a espécie utilizada no experimento. A espécie de escorpião utilizado, é popularmente conhecido no Brasil como escorpião-amarelo, de nome científico - T. serrulatus. Os escorpiões pertencem ao Filo Arthropoda, Subfilo Cheliceriformes, Classe Chelicerata, Subclasse Arachnida e Ordem Scorpiones. (Brazil e Porto, 2017). O escorpião-amarelo, possui a região do cefalotórax e mesosoma mais escurecidos, possuindo um tamanho que varia de 5 a 7 centímetros e distribuem-se na região Sudeste do Brasil, Paraná, sul de Goiás e Bahia (Guidolin, Ferreti e Nishida, 2022).

Na Figura 1, encontram-se dispostos, os resultados da aula prática proposta. Com a luz ambiente, ou com a lanterna de luz branca ou amarela podemos observar na Figura 1a, que a coloração do escorpião permaneceu a mesma, ou seja não ocorreu alteração no seu padrão externo de cor. Agora, quando iluminado no ambiente escuro, com apenas a luz negra, o escorpião-amarelo adquiriu uma coloração azul brilhante (fluorescente) (Figura 1b). Nessa parte da atividade, o professor poderá sugerir aos alunos que formulem e respondam hipóteses para o fenômeno observado. As hipóteses mais comuns podem ser: "Deve ocorrer algo na luz que faz com que o escorpião mude de cor" ou "Deve existir algo na parte externa do escorpião que ao reagir com a luz negra, altera o seu padrão de cor.

O professor deverá explicar aos alunos que essa mudança no padrão da cor externa do escorpião-amarelo, para um padrão de tom azul brilhante, pode estar relacionada aos escorpiões perceberem as alterações de luz do meio, principalmente quando iluminados com a luz negra e luz ultravioleta. Segundo estudos realizados com escorpiões da espécie Paruroctonus utahensis, Gaffin et al. (2012) relataram que o exoesqueleto dos escorpiões é formado principalmente pelo polissacarídeo quitina em associação com algumas proteínas (Pechenik, 2016), moléculas essas que podem ser responsáveis pelo fenômeno de fluorescência. É importante ressaltar aos alunos que a quitina, atua na proteção, sustentação e movimento, proporcionando um rígido sistema esquelético ao organismo (Pechenik, 2016). 
Assim, segundo Gaffin et al. (2012), a estrutura corporal desses organismos permite captar a luz ultravioleta (luz negra) emitindo uma cor verde ciano (azul brilhante fluorescente). Na literatura, existem muitas hipóteses para explicar o porquê deste fenômeno tão curioso. Uma delas, pode ser denominada de aposematismo, ou seja, é quando outras espécies percebem uma característica singular no organismo (neste caso, é a fluorescência emitida pela superfície externa dos escorpiões em contato com a luz negra), e se assustam, para não tornar suas presas, afastando-se do animal (Kloock, 2005; Gaffin et al., 2012). De outro modo, a fluorescência emitida em contanto com a luz UV, ou negra, funcionam como um mecanismo de atração de presas. Outros insetos e animais se sentem atraídos e curiosos ao perceberem esse padrão de luz emitida, tornando-se presas fáceis (Haddock e Dunn, 2015).

Figura 1 - Escorpião-amarelo (T. serrulatus) iluminado com luz normal (a) e iluminado com luz negra (b).

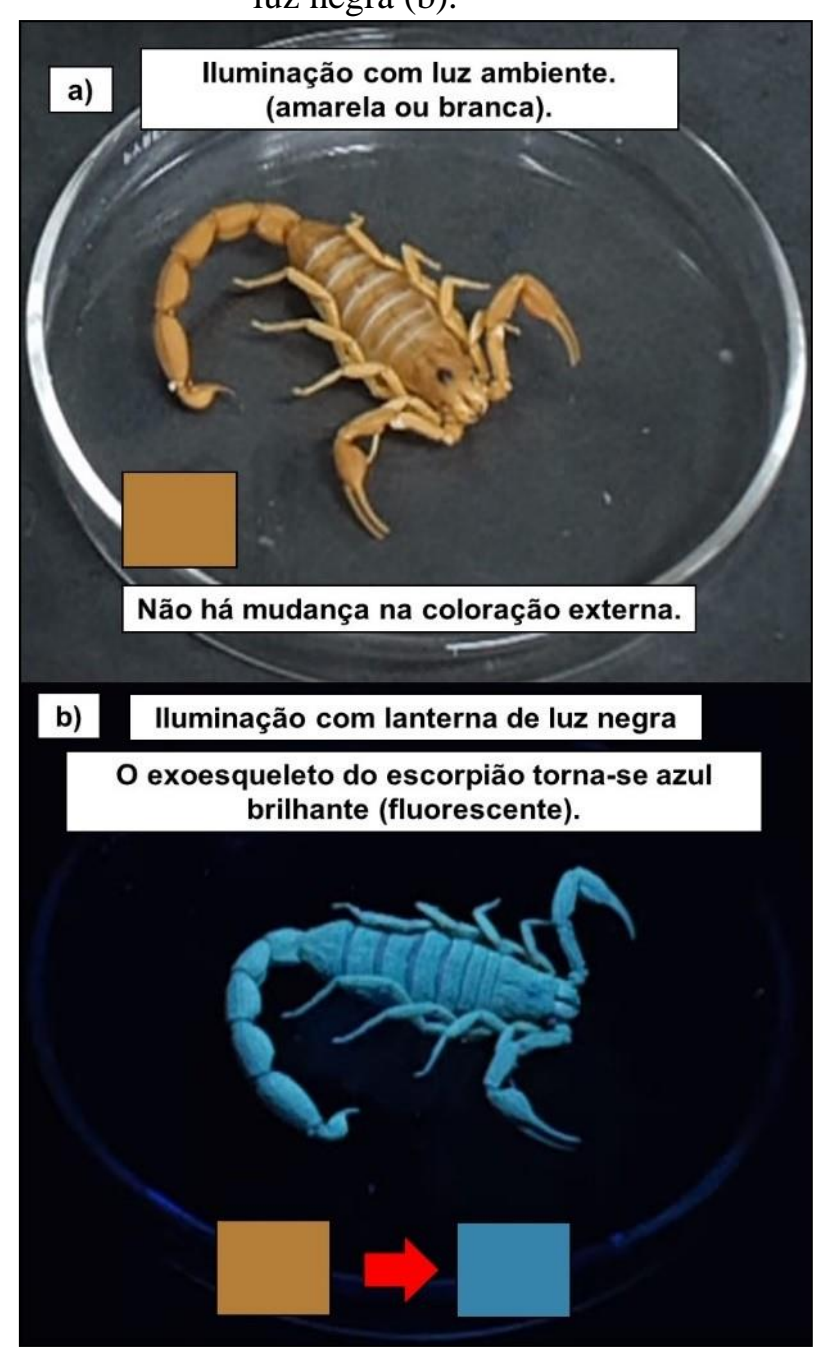

Fonte: Foto gentilmente cedida de uma captura de vídeo de Amorim (2015) com modificações do Autor (2022). 
Brites-Neto e Galassi (2012) discutem que esse curioso fenômeno de mudança de coloração extracorpórea nos escorpiões é muito interessante, pois permite auxiliar na coleta desses organismos. Neste caso, o autor explica que a luz azul emitida pelo corpo dos escorpiões quando iluminados por meio da luz negra, é facilmente percebida pelo olho humano, facilitando-se sua coleta em período noturno. No nosso país, até mesmo muitos agentes que trabalham em dedetização, costumam utilizar essa técnica de luz negra ou ultravioleta para capturarem os escorpiões no período noturno, principalmente em cemitérios, ruas e lotes abandonados, controlando-se assim uma possível infestação.

No segundo momento da aula prática, o professor poderá explicar aos alunos, sobre as características morfológicas e fisiológicas desses organismos, manipulando suas estruturas corporais por meio de uma pinça, para toda a turma. Na figura 2, encontra-se disposto a foto da vista dorsal, de um exemplar da espécie de escorpião-amarelo ( $T$. serrulatus).

Figura 2 - Vista dorsal da estrutura corporal da espécie (T. serrulatus), escorpião-amarelo. Os números, representam as divisões dos segmentos corporais do animal.

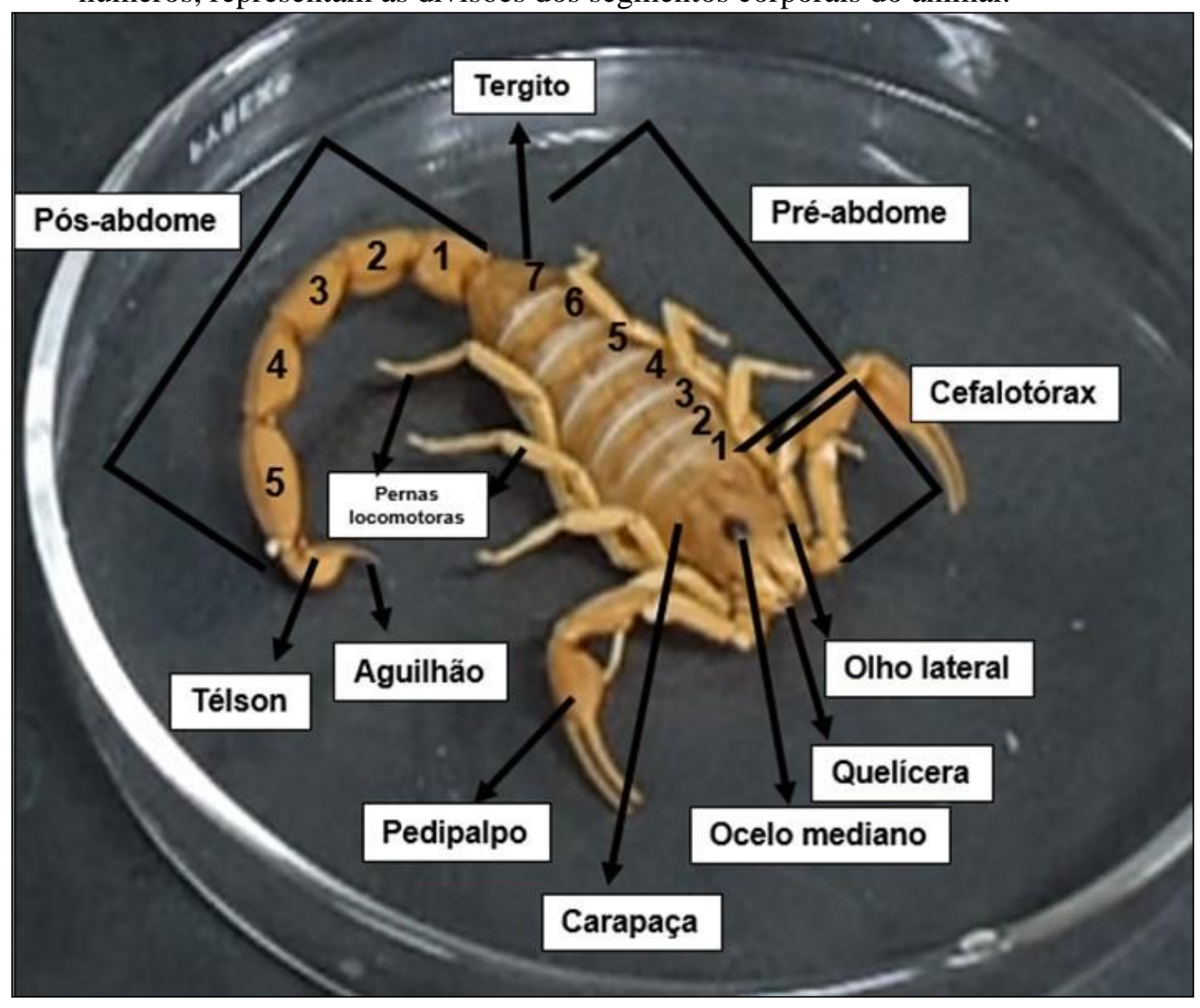

Fonte: Foto gentilmente cedida de uma captura de vídeo de Amorim (2015) com modificações do Autor (2022). 
$\mathrm{Na}$ vista dorsal, o professor poderá comentar com os alunos que o corpo dos escorpiões é dividido em 3 partes: cefalotórax ou prosoma, opistosoma composto pelo mesosoma (pré-abdome) e o metasoma (pós-abdome). Segundo Brazil e Porto (2017), os escorpiões possuem 4 pares de pernas locomotoras, um par de quelíceras, um par de pedipalpos, apresentando características singulares entre os aracnídeos, como a presença de pentes (Figura 3a) e a modificação do télson que possui glândulas de veneno e aguilhão (Figura 3b). As quelíceras trissegmentadas possuem como principal função a de trituração do alimento já, os pentes sensoriais (Figura 3a), segundo Brazil e Porto (2017, p. 814) é uma:

\begin{abstract}
"estrutura exclusiva dos escorpiões que funcionam como quimiorreceptores e mecanorreceptores, importantes para percepção da presa, orientação espacial e, para os machos, busca de fêmeas. Com o propósito de facilitar o encontro para a cópula, a fêmea, quando receptiva, pode emitir um feromônio que direciona o macho ao encontro dela" (Brazil e Porto, 2017, p. 814).
\end{abstract}

Ainda, na Figura 3a (centro), aparece o opérculo genital, estrutura que protege os órgãos genitais, e permite nas fêmeas a saída dos filhotes durante o parto. Na figura 3b, está disposto o aparato de veneno dos escorpiões. Segundo Brazil e Porto (2017, p. 814), "a inoculação do veneno ocorre pelo télson, composto por uma vesícula que comporta 2 glândulas de veneno, e o ferrão".

Figura 3 - Estruturas corporais do escorpião. a) vista ventral e b) aparato de veneno.

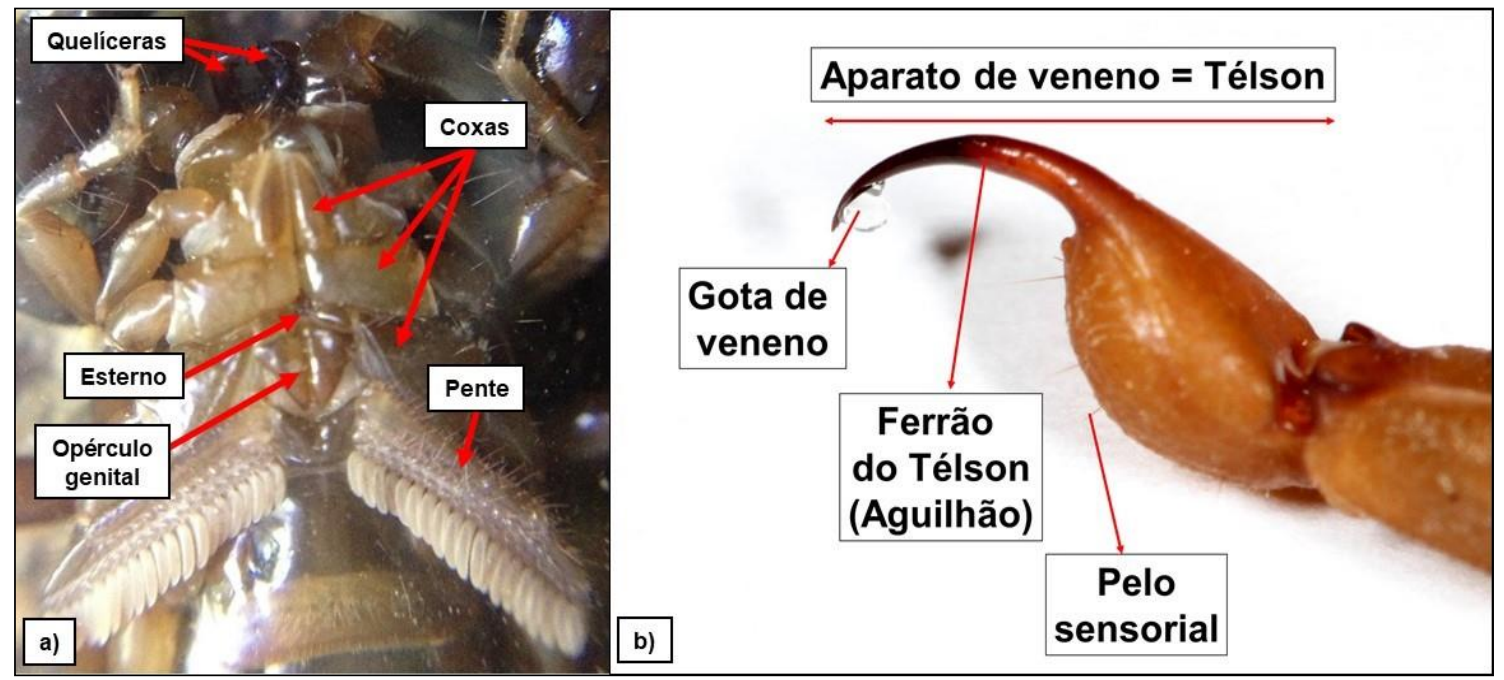

Fonte: Figura 3a, modificado de Wikimedia Commons (2022a). Disponível em:

https://commons.wikimedia.org/wiki/File:Vista_ventral_de_un_escorpi\%C3\%B3n.jp e Figura

3b, modificado de Wikimedia Commons (2022b). Disponível em:

https://commons.wikimedia.org/wiki/File:Scorpion_tail_(6122405259).jpg 
No que tange aos aspectos Fisiológicos dos escorpiões, o professor poderá comentar com os alunos que os mesmos possuem respiração aérea, desempenhada por pulmões foliáceos, com a abertura externa, pela estrutura denominada estigma (ocorrendo 1 par por cada segmento) (Brazil e Porto, 2017). O sistema respiratório é lacunar ou aberto e o sistema nervoso é formado por um gânglio cerebral central fundidos na região do cefalotórax (prosoma). Segundo Brazil e Porto (2017, p. 813), os escorpiões possuem, "um par de olhos medianos e 2 a 5 pares de olhos laterais, os quais são extremamente sensíveis à luz e eficientes para os hábitos noturnos do animal".

Os escorpiões são carnívoros e se alimentam de pequenos insetos e pequenas aves e répteis. Eles utilizam o seu veneno para geralmente imobilizar a sua presa, servindo também para degradar parte do seu alimento. Os escorpiões utilizam suas quelíceras para manipular e auxiliar na maceração do seu alimento, regurgitando sucos digestivos intestinais repletos de enzimas capazes de facilitar a digestão do animal capturado. A digestão, portanto, é externa (extra-corpórea) e o resultado é um líquido pastoso que é sugado, e internamente, vai para o sistema digestivo completo para que ocorra a digestão intracelular e conseguinte absorção dos nutrientes. É interessante ressaltar aos alunos, que os escorpiões são muito resistentes, e conseguem ficar meses sem se alimentar, podendo também, não fazerem o uso da ingestão de água, tornando o seu combate uma tarefa muito dificultada (FUNASA, 2001).

No que tange aos aspectos reprodutivos, Brazil e Porto (2017, p. 814) destacam que:

\footnotetext{
“Os escorpiões são vivíparos, os filhotes nascem pelo opérculo genital e sobem no dorso da mãe (cuidado parental), região do corpo na qual permanecem por volta de 2 a 3 semanas antes de se dispersarem. Alguns escorpiões reproduzem-se assexuadamente por partenogênese, como o Tityus serrulatus (família Buthidae)" (Brazil e Porto, 2017, p. 814).
}

Além do escorpião-amarelo, no Brasil, ocorre a espécie popularmente conhecida como escorpião-marrom, representada pela espécie $T$. bahiensis, é uma espécie sexuada e possui uma coloração corpórea marrom avermelhada. Essa espécie também é bastante venenosa, e ocorre nas regiões Sul e Sudeste, sul de Minas Gerais, possuindo tamanho médio de 5 a $7 \mathrm{~cm}$ (Guidolin, Ferreti e Nishida, 2022).

Por fim, o professor pode encerrar a aula, alertando os alunos sobre os cuidados que devemos tomar, inerentes aos escorpiões. Ao ser picado por um escorpião, é 
recomendado fazer uma compressa morna, aliviando o quadro até a chegada no hospital, não é recomendado o uso de torniquetes, pomadas e de gelo no local da picada. (BUTANTAN, 2022). A pessoa picada deverá ser encaminhada ao serviço hospitalar para a administração de "soro antiescorpiônico (SAEEs) ou antiaracnídico (SAAr) aos pacientes com formas moderadas e graves de escorpionismo, que são mais freqüentes nas crianças picadas pelo Tityus serrulatus (8\% a $10 \%$ dos casos)" (FUNASA, 2001, p. 43). Segundo Butantan (2022, sp), os principais cuidados para se evitar acidentes envolvendo escorpiões são:

\footnotetext{
"Manter jardins e quintais limpos. Evitar folhagens densas junto a paredes e muros das casas e manter a grama aparada. Não colocar as mãos em buracos, sob pedras e em troncos podres. Usar calçados e luvas grossas nas atividades de jardinagem. Vedar ralos, frestas, buracos e soleiras de portas e janelas. Afastar as camas e berços das paredes, evitar que roupas de cama e mosquiteiros encostem no chão. Sacudir e verificar roupas e sapatos antes de usá-los. Preservar os predadores naturais: coruja, joão-bobo, lagartos, sapos, galinhas, gansos e quatis" (Butantan, 2022, sp).
}

\section{CONCLUSÃO}

$\mathrm{Na}$ área da Zoologia, como em toda a Biologia, o uso de aulas experimentais pode ser de grande impacto, pois permite facilitar o processo de ensino e aprendizagem dos estudantes, transpondo na prática o que foi aprendido na teoria. Além de que, essa modalidade didática, tem o papel de favorecer o lado criativo e científico dos discentes, desenvolvendo a ótica de experimentação em ciências.

Como sugestão de abordagem futura, o professor poderá propor outras metodologias de ensino, aplicadas na Zoologia, como o uso de jogos lúdicos ou gincanas, potencializando ainda mais a aprendizagem dos alunos. 


\section{REFERÊNCIAS}

AMORIM, A. Escorpiões brilham no escuro! Por quê? Youtube, Canal Alex Amorim (2015). Disponível em: https://www.youtube.com/watch?v=4-QYzt0sGX8 Acesso em: 18 fev. 2022.

BRAZIL, T. K.; PORTO, T. J. Cheliceriformes. In: FRANSOZO, A.; NEGREIROSFRANSOZO, M. L. Zoologia dos Invertebrados. Rio de Janeiro: Editora Roca, 2017. p. 794-827.

BRITES-NETO, J.; G.G. GALASSI. Monitoramento epidemiológico de Tityus serrulatus em áreas urbanas, mediante uso de luz ultravioleta. Vetores \& Pragas, v, 30, p. 16-18, 2012. Disponível em:

https://www.researchgate.net/publication/258423140_Monitoramento_epidemiologico_ de_Tityus_serrulatus_em_areas_urbanas_mediante_dispositivo_de_luz_ultravioleta Acesso em: 18 fev. 2022.

BUTANTAN. Primeiros socorros (2022). Disponível em:

https://butantan.gov.br/atendimento-medico/primeiro-socorros Acesso em: 18 fev. 2022.

DE ALBUQUERQUE, F. P.; MILLÉO, J.; DE LIMA, J. M. M.; BARBOLA, I. F. Entomologia no ensino médio técnico agrícola: Uma proposta de trabalho. Revista Eletrônica de Educação, v. 8, n. 3, p. 251-265, 2014. Disponível em:

http://dx.doi.org/10.14244/198271991030 Acesso em: 18 fev. 2022.

ELIAS, J. A.; CARVALHO, A. C.; MÓL, G. S. O escorpião fluorescente: Uma proposta interdisciplinar para o Ensino Médio. Revista Química Nova na Escola. v. 39, n. 3, p. 286-290, 2017. Disponível em:

http://qnesc.sbq.org.br/online/qnesc39_3/10-EEQ-60-16.pdf Acesso em: 18 fev. 2022.

FUNASA. Fundação Nacional de Saúde. Manual de Diagnóstico e Tratamento de Acidentes por Animais Peçonhentos. Brasília. (2001). Disponível em:

https://www.icict.fiocruz.br/sites/www.icict.fiocruz.br/files/Manual-de-Diagnostico-eTratamento-de-Acidentes-por-Animais-Pe--onhentos.pdf Acesso em: 18 fev. 2022.

GAFFIN, D. D.; BUMM, L. A.; TAYLOR, M. S.; POPOKINA, N. V.; MANN, S. Scorpion fluorescence and reaction to light. Animal Behaviour, v. 83, p. 429-436, 2012. Disponível em: http://dx.doi.org/10.1016/j.anbehav.2011.11.014 Acesso em: 18 fev. 2022.

GONÇALVES, T. M. Na teia do saber: Utilizando o filme "Aracnofobia" para potencializar a aprendizagem de Zoologia no Ensino Médio. Research, Society and Development, v. 10, n. 5, p. 1-10, 2021a. Disponível em:

http://dx.doi.org/10.33448/rsd-v10i5.14619 Acesso em: 18 fev. 2022.

GONÇALVES, T. M. A guerra imunológica das células contra os patógenos: a proposta de um modelo didático tridimensional de baixo custo para simulação da resposta imune celular mediada por linfócitos T CD8 ${ }^{+}$. Brazilian Journal of Development, v.7, n.1, p. 4854-4860, 2021b. Disponível em: 
https://www.brazilianjournals.com/index.php/BRJD/article/view/23099 Acesso em: 18 fev. 2022.

GUIDOLIN, F. R.; FERRETE, B. L. S.; NISHIDA, S. M. Importância médica e biológica. $\mathrm{O}$ que acontece se for picado por escorpião? Animais sinantrópicos, escorpiões, UNESP. 2022. Disponível em:

https://www2.ibb.unesp.br/Museu_Escola/2_qualidade_vida_humana/Animais_domesti cos_sinatropicos/escorpiao/interesse_medico_biologia.htm Acesso em: 18 fev. 2022.

HADDOCK, S. H.; DUNN, C. W. Fluorescent proteins function as a prey attractant: experimental evidence from the hydromedusa Olindias formosus and other marine organisms. Biol Open. v. 31, n. 4, s. 9, p.1094-104, 2015. Disponível em:

https://www.ncbi.nlm.nih.gov/pmc/articles/PMC4582119/ Acesso em: 18 fev. 2022.

INEP. Instituto Nacional de Estudos e Pesquisas Educacionais Anísio Teixeira. Dados do censo escolar, 2019. Disponível em:

https://www.gov.br/inep/pt-br/assuntos/noticias/censo-escolar/dados-do-censo-escolar-noventa-e-cinco-por-cento-das-escolas-de-ensino-medio-tem-acesso-a-internet-masapenas-44-tem-laboratorio-de-ciencias Acesso em: 18 fev. 2022.

KLOOCK, C. T. Aerial insects avoid fluorescing scorpions. Euscorpius, v, 21, p. 1-7, 2005. Disponível em:

https://mds.marshall.edu/cgi/viewcontent.cgi?article=1059\&context=euscorpius

Acesso em: 18 fev. 2022.

KRASILCHIK, M. Prática de Ensino de Biologia. 4ª ed. Edusp, São Paulo, 2019.

MARANDINO, M.; SELLES, S. E.; FERREIRA, M. S. Ensino de Biologia: histórias e práticas em diferentes espaços educativos. $1^{a}$ ed. São Paulo: Cortez Editora, 2009.

PECHENIK, J. A. Biologia dos invertebrados. Porto Alegre: AMGH, 2016.

WIKIMEDIA COMMONS. Vista ventral de un escorpión, (2022a). Disponível em: https://commons.wikimedia.org/wiki/File:Vista_ventral_de_un_escorpi\%C3\%B3n.jpg Acesso em: 18 fev. 2022.

WIKIMEDIA COMMONS. Scorpion tail, (2022b). Disponível em: https://commons.wikimedia.org/wiki/File:Scorpion_tail_(6122405259).jpg. Acesso em: 18 fev. 2022.

Recebido em: 20/01/2022

Aprovado em: 21/02/2022

Publicado em: 24/02/2022 